\title{
Numerical simulation of thermal behavior and multicomponent mass transfer in direct laser deposition of Co-base alloy on steel
}

\author{
Zhengtao Gan, Gang Yu* , Xiuli He, Shaoxia Li \\ Key Laboratory of Mechanics in Advanced Manufacturing, Institute of Mechanics, Chinese Academy of Sciences, Beijing 100190, People's Republic of China
}

\section{A R T I C L E I N F O}

\section{Article history:}

Received 14 April 2016

Accepted 13 August 2016

Available online 20 August 2016

\section{Keywords:}

Laser cladding

Thermal behavior

Solidification

Multicomponent mass transfer

\begin{abstract}
A B S T R A C T
During direct laser deposition process, rapid melting-solidification and addition of multicomponent powder lead to complex transport phenomena in the melt pool. The thermal behavior and mass transport significantly affect the solidified microstructure and properties of fabricated layer. In this paper, an improved 3D numerical model is proposed to simulate the heat transfer, fluid flow, solidification and multicomponent mass transport in direct laser deposition of Co-base alloy on steel. The solidification characteristics, including temperature gradient $(G)$, solidification growth rate $(R)$ and cooing rate $(G \times R)$, can be obtained by transient thermal distribution to predict the morphology and scale of the solidification microstructure. Multicomponent transport equation based on a mixture-averaged approach is combined with other conservation equations. The calculated melt pool geometry and the composition profiles of iron (Fe), carbon (C), cobalt (Co) and chromium ( $\mathrm{Cr}$ ) are compared with the experimental results. The results show that in the initial stage of direct laser deposition, the rapidly mixture of substrate material and added material occur in the melt pool and conduct plays an important role in heat transfer due to the low Peclet number. As the melt pool is developed, the heat and mass transfer in the melt pool are dominated by strong Marangoni convection. An unmixed zone is observed near the bottom of melt pool where the convection is frictionally dissipated due to the presence of solidified dendrites. Since the $G / R$ decreases and $G \times R$ increases from the bottom to the top of the solidified track, the morphology of the microstructure changes from planar front to columnar dendrites to equiaxed dendrites and the grain size decreases.
\end{abstract}

(c) 2016 Elsevier Ltd. All rights reserved.

\section{Introduction}

Direct laser deposition, as an advanced additive manufacturing technology, provides an attractive tool to fabricate functionally gradient materials. It has some benefits compared with the traditional surface modification and manufacture technique, such as its small heat affected zone, low thermal strain, low porosity, and finer grain size [1,2]. In direct laser deposition, the substrate is melted by a high power density laser beam creating a melt pool in which the multicomponent alloy powders are injected [3]. Cobase and Ni-base alloy have been widely used as the added material to improve the surface properties of substrate, such as strength, wear resistance and corrosion resistance [4-6]. In spite of its widespread application, an understanding of transport phenomena and solidification behavior in the melt pool still remains as a challenge.

\footnotetext{
* Corresponding author.

E-mail address: gyu@imech.ac.cn (G. Yu).
}

During this process, metallic powders addition into the melt pool result in the redistribution of alloy elements in the melt pool $[7,8]$. Due to the difference in chemical composition and thermophysical property of substrate and added material, a great deal of defects, involving the non-fusion owing to insufficient heat transfer, the formation of brittle intermetallic compound and low melting point eutectics owing to inappropriate solute transport, all make the deposited layer prone to crack and failure $[9,4,10]$. Selecting appropriate composition of powder material and thermophysical property is an approach to overcome the problem and obtain ideal deposited layer properties. However, a large number of trial experiments are time-consuming and money-consuming. Numerical simulation has offered an effective tool in prediction the thermal behavior and mass transport in direct laser deposition [11-22]. A three-dimensional mathematical model has been established in which the temperature field and flow field is obtained [11]. In order to simulate mass addition process, the level set approach was introduced into the numerical model to capture the liquid/gas interface of melt pool. The direct metal deposition was studied by a 3D numerical model [12]. The transport phenom- 
ena including heat transfer and fluid flow were investigated and analyzed. Kumar et al. [13] proposed and solved sets of dimensionless transport equations to investigate the laser metal deposition process. Deposited track geometry, dilution rate and maximum melt pool temperatures were calculated. Lee et al. [14] developed a three-dimensional transport model to understand the melt pool formation, liquid metal flow and the evolution of surface tension in Inconel 718 laser deposition.

The heat transfer affects the solidification behavior of deposited track. Few studies tried to obtain the solidification characteristics of deposited track depending on computed temperature distribution. A 3D thermal FEM model has been built to calculate the temperature variation, the cooling rate and the solidifying rate in the solid-liquid interface [15]. Using a Fourier heat conduction model, the effect of substrate temperature and cooling rates on the distribution of added particles was investigated [16]. However, the Marangoni convection caused by the thermocapillary effect did not consider in these numerical models.

Although numerical simulation has previously offered a tool of effective evaluating the thermal behavior during the direct laser deposition process [11-18], few models considered the mass transfer in this process. Huang et al. [19] studied the heat and mass transport during the laser metal deposition process. The dualequation of mass transfer was utilized to calculate separately the composition profile between deposited layer and base metal. He et al. [20,21] proposed a 3D transient heat and mass transfer model to predict the solute distribution in the deposited layer. The mathematical model was calculated by solving the species conservation equations besides the energy and momentum conservation equations. The binary system $\mathrm{Fe}-\mathrm{C}$ and $\mathrm{Fe}-\mathrm{Cr}$ were evaluated to obtain the concentration distribution of $\mathrm{C}$ and $\mathrm{Cr}$ [20]. The solute transfer and composition profiles evolution for binary system $\mathrm{Fe}-\mathrm{C}$ during double-track direct metal deposition also have been reported [21]. Although the multicomponent mass transfer model has been built in metal casting and chemical engineering [22,23], such study for direct laser deposition has not been reported in the open peerreviewed literature.

In this paper, a self-consistent model, including thermal behavior, liquid metal flow, solidification and multicomponent mass transfer, are investigated in direct laser deposition. The temperature gradient $(G)$ and solidification growth rate $(R)$ are obtained by thermal analysis to predict the morphology and scale of the solidification microstructure. To consider the multicomponent convection and diffusion in the movable melt pool, multicomponent transport equation based on a mixture-averaged approach is combined with the equations of mass, momentum and energy conservation. The composition profiles of iron ( $\mathrm{Fe})$, carbon $(\mathrm{C})$, cobalt (Co) and chromium $(\mathrm{Cr})$ in the deposited track are also present. The computed melt pool geometry and composition profiles are compared with the experimental results. The present study demonstrates the numerical simulation of transport phenomena can generate significant insight into details of thermal behavior and multicomponent mass transport in direct laser deposition.

\section{Experimental procedure}

38MnVS medium carbon steel and Co-base alloy powder are selected as substrate and added material. Table 1 shows the com-

Table 1

Material composition of 38MnVS carbon steel and Co-Cr-W powder (weight \%).

\begin{tabular}{lllllllll}
\hline & Fe & C & Co & Mn & Cr & W & V & S \\
\hline 38MnVS & Bal & 0.38 & - & 1.4 & 0.16 & - & 0.5 & 0.04 \\
Co-Cr-W & - & 0.35 & Bal & 1.8 & 20 & 3 & - & - \\
\hline
\end{tabular}

positions of material. Fig. 1 shows the schematic diagram of experimental setup. Direct laser deposition was implemented on a $1000 \mathrm{~W}$ Nd: YAG laser manufacturing system with six-axis programmed control platform. The focal length of lens is $160 \mathrm{~mm}$. The pattern of laser beam is multi-mode and the beam radius is set to $1 \mathrm{~mm}$ (defocus of beam is $10 \mathrm{~mm}$ ). Two feeding pipes are used to delivery powder into melt pool. High purity argon is used as shielding gas. Samples of the substrate were prepared in the size of $20 \mathrm{~mm} \times 10 \mathrm{~mm} \times 6 \mathrm{~mm}$. Metallographic samples were prepared by electric discharge cutting, mechanical milling and grinding, followed by standard mechanical polishing and then etched in aqua regia solution. In order to examine the solidified microstructure and concentration of alloy element, the samples were characterized by JSM-6460 scanning electron microscopy (SEM) equipped with Oxford INCA energy dispersive spectrometer (EDS).

\section{Mathematical model}

A mathematical model involving heat transfer, fluid flow and mass transfer in direct laser deposition is proposed. The simplifying assumptions are the following $[11,20]$ :

1. The fluid flow in the melt pool is assumed to be Newtonian, laminar and incompressible.

2. The thermophysical properties of powder and substrate are assumed to be temperature-independent.

3. The laser heat flux is assumed to be a Gaussian distribution.

4. The heat flux of the heated powder and the heat loss by evaporation are neglected.

5. The mushy zone where the temperature is between the solidus and liquidus is assumed as a porous medium with isotropic permeability.

6. There is no diffusion transport in solid phase.

7. The concentration distribution of powder flow is assumed to be Gaussian. Powders falling in the region of melt pool are melted immediately.

8. The energy attenuation of laser beam through the powder flow is neglected.

\subsection{Governing equations}

The equations of conservation of mass, momentum-transport, thermal energy and species concentration are formulated as Eqs. (1)-(4).

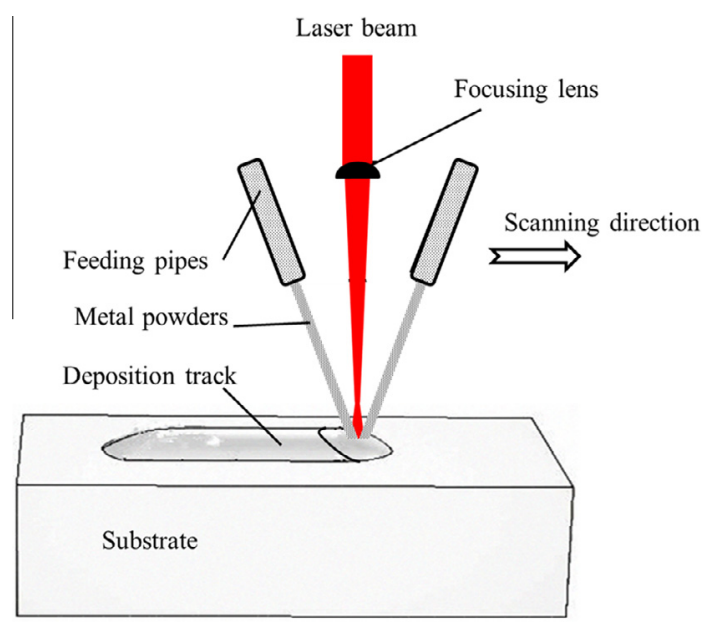

Fig. 1. Schematic diagram of experimental setup for direct laser deposition. 
$\frac{\partial \rho}{\partial t}+\nabla \cdot(\rho \boldsymbol{u})=0$

$\rho \frac{\partial \boldsymbol{u}}{\partial t}+\rho(\boldsymbol{u} \cdot \nabla) \boldsymbol{u}=\nabla \cdot\left[-p \boldsymbol{I}+\mu\left(\nabla \boldsymbol{u}+(\nabla \boldsymbol{u})^{T}\right)-\frac{2 \mu}{3}(\nabla \cdot \boldsymbol{u}) \boldsymbol{I}\right]-K_{0} \frac{\left(1-f_{l}\right)^{2}}{f_{l}^{3}+B} \boldsymbol{u}$

$\rho c_{p}\left(\frac{\partial T}{\partial t}+\boldsymbol{u} \cdot \nabla T\right)=\nabla \cdot(k \nabla T)-\frac{\partial H}{\partial t}-\rho \boldsymbol{u} \cdot \nabla H$

$$
\begin{gathered}
\rho \frac{\partial C_{i}}{\partial t}+\rho(\boldsymbol{u} \cdot \nabla) C_{i}=\nabla \cdot\left(\rho D_{i}^{m} \nabla C_{i}+\rho C_{i} D_{i}^{m} \frac{\nabla M_{n}}{M_{n}}\right) \\
+\nabla \cdot\left(\rho D_{i}^{m} \nabla\left(C_{l}-C_{i}\right)\right)-\nabla \cdot\left(\rho f_{s} \nabla\left(C_{l}-C_{s}\right) \boldsymbol{u}\right)
\end{gathered}
$$

where $\rho$ is the density, $t$ is the time, $\boldsymbol{u}$ is the velocity of liquid metal, $\mu$ is the viscosity, $p$ is pressure, $T$ is the temperature, $c_{p}$ is the specific heat, and $k$ is the thermal conductivity. The last term in the right side of Eq. (2) represents the momentum dissipation in the mushy zone, which is quantified depending on the Carman-Kozeny equation [24]. $K_{0}$ is a constant depending on the morphology of the porous media $\left(2 \times 10^{7}\right.$ in this study). $B$ is a small number to avoid division by zero $\left(1 \times 10^{-3}\right.$ in this study) [25,26]. In Eq. (3), $H$ is the latent enthalpy content of the fusion, which is given as,

$\Delta H=L f_{l}$

where the liquid mass fraction $\mathrm{f}_{\mathrm{l}}$ is defined as,

$f_{l}=\left\{\begin{array}{cc}1, & T>T_{l} \\ \frac{T-T_{s}}{T_{l}-T_{s}}, & T_{s} \leqslant T \leqslant T_{l} \\ 0, & T<T_{s}\end{array}\right.$

where the subscripts $s$ and $l$ denote the solid phase and liquid phase. $f$ and $g$ represent the mass fraction and volume fraction, the thermophysical properties in the domain are defined as [27],

$C_{i}=f_{s} C_{i_{s}}+f_{l} C_{i_{l}}$,

$c_{p}=f_{s} c_{p s}+f_{l} c_{p l}$

$\rho=f_{s} \rho_{s}+f_{l} \rho_{l}$

$k=\left(\frac{g_{s}}{k_{s}}+\frac{g_{l}}{k_{l}}\right)^{-1}$

$D_{i}^{m}=f_{l} D_{i}^{m}$

The mass transport of the major elements, $\mathrm{Fe}, \mathrm{C}, \mathrm{Co}$ and $\mathrm{Cr}$ are calculated based on multicomponent transport Eq. (4). $C_{i}$ is the concentration of the $i$ th species. The first term in the right side of Eq. (4) is multicomponent diffusion term. Mixture-averaged approach is used to simulate the multicomponent diffusion mechanism [28]. $D_{i}^{m}$ and $M_{n}$ is the multicomponent mixture-averaged diffusion coefficient and mixture-averaged molar mass, respectively, which are calculated as follow [28],

$D_{i}^{m}=\frac{1-f_{i}}{\sum_{k \neq i} \frac{\chi_{k}}{D_{i k}}}$

$M_{n}=\left(\sum_{i} \frac{f_{i}}{M_{i}}\right)^{-1}$,

where $\chi_{i}$ is the mole fraction of the $i$ th species, $f_{i}$ is the mass fraction of the $i$ th species, $D_{i k}$ is the multicomponent Maxwell-Stefan diffusivities, which are supplied as inputs to the model, $M_{i}$ is the molar mass of the $i$ th species. The second and third terms in the right side of Eq. (4) represent the concentration flux owing to the diffusion and convection of phase change, respectively. In pure liquid or solid phase, their effect can be neglected [27].

\subsection{Boundary and initial conditions}

The laser heat flux input at liquid/gas interface is as follow,

$$
\begin{aligned}
q_{\text {ener }}= & \frac{2 Q \eta_{l}}{\pi r_{b}^{2}} \exp \left(\frac{-2\left(\left(x-V_{s} t\right)^{2}+y^{2}\right)}{r_{b}^{2}}\right)-h_{c}\left(T-T_{0}\right) \\
& -\sigma_{b} \varepsilon\left(T^{4}-T_{0}^{4}\right)
\end{aligned}
$$

The three terms in the Eq. (13) account for the laser heat flux and the heat loss by convection and radiation, respectively. $Q$ is the laser power, $\eta_{l}$ is the absorptance of laser energy, $r_{b}$ is the effective laser beam radius, $x$ and $y$ are the distances to the laser beam, $V_{s}$ is the scanning speed, $h_{c}$ is the heat transfer coefficient, $\sigma_{b}$ is the Stefan-Boltzmann constant, $\varepsilon$ is the emissivity and $T_{0}$ is the ambient temperature.

The boundary condition of momentum equation at liquid/gas interface are given by [20],

$F_{L / G}=\sigma \boldsymbol{n}^{*} \kappa-\nabla_{s} T \frac{d \sigma}{d T}$

The two terms in the Eq. (14) represent the capillary force and thermocapillary force, respectively. $\sigma$ is the surface tension, $\boldsymbol{n}^{*}$ is the normal of surface and $\kappa$ is the curvature of surface.

The dynamic shape of the melt pool surface is explicitly described by a moving mesh based on an arbitrary LagrangianEulerian method (ALE) [29]. Two kinds of velocities are considered at liquid/gas interface - the fluid flow velocity and boundary moving velocity due to mass addition [18]. They can be formulated as,

$V_{L / G}=\boldsymbol{u} \cdot \boldsymbol{n}^{*}+\boldsymbol{V}_{\boldsymbol{p}} \cdot \boldsymbol{n}^{*}$,

where $\boldsymbol{u}$ is the fluid flow velocity at liquid/gas interface. $\boldsymbol{V}_{\boldsymbol{p}}$ represents the moving velocity of liquid/gas interface due to mass addition. The calculation of $\boldsymbol{V}_{\boldsymbol{p}}$ is given by,

$\boldsymbol{V}_{p}=\frac{2 m_{f} \eta_{m}}{\rho_{m} \pi r_{p}^{2}} \exp \left(\frac{-2\left(\left(x-V_{s} t\right)^{2}+y^{2}\right)}{r_{p}^{2}}\right) \boldsymbol{z}$

where $m_{f}$ is the mass flow rate, $\eta_{m}$ is powder catchment efficiency, $\rho_{m}$ is the density of powder and $r_{p}$ is the mass flow radius, $\boldsymbol{z}$ is unit vector in the $z$ direction.

The boundary condition for concentration equation at liquid/gas interface can be formulated as,

$q_{c o}=\chi_{c o} \frac{2 m_{f} \eta_{m}}{M_{c o} \pi r_{p}^{2}} \exp \left(\frac{-2\left(\left(x-V_{s} t\right)^{2}+y^{2}\right)}{r_{p}^{2}}\right)$

$q_{c r}=\chi_{c r} \frac{2 m_{f} \eta_{m}}{M_{c r} \pi r_{p}^{2}} \exp \left(\frac{-2\left(\left(x-V_{s} t\right)^{2}+y^{2}\right)}{r_{p}^{2}}\right)$

$q_{c o}$ and $q_{c r}$ are the concentration flux of elemental Co and $\mathrm{Cr}$, respectively. $\chi_{c o}$ and $\chi_{c r}$ are the molar fraction of elemental $\mathrm{Co}$ and $\mathrm{Cr}$ in the powder, respectively, which can obtain from Table $1 . M_{c o}$ and $M_{c r}$ are the molar mass of elemental $\mathrm{Co}$ and $\mathrm{Cr}$, respectively.

The initial temperature in the workpiece is $293 \mathrm{~K}$. The initial velocity is zero. The initial mass fractions of $\mathrm{Fe}, \mathrm{C}, \mathrm{Co}, \mathrm{Cr}$ in the workpiece are $99.6 \%, 0.4 \%, 0$ and 0 .

A 3D orthogonal coordinate system was established in the study. Only half of workpiece was taken into account. The equations were solved by using SIMPLE solver. A minimum size of $20 \mu \mathrm{m}$ and a maximum size of $50 \mu \mathrm{m}$ were specified in the domain. A maximum time step of $1 \times 10^{-4} \mathrm{~s}$ was employed. This model was computed using a Dell T5500 computing station $(12 \times 2.5 \mathrm{GHz}-$ $24 \mathrm{~GB}$ ). The four components ( $\mathrm{Fe}, \mathrm{C}, \mathrm{Co}, \mathrm{Cr}$ ) were included in this 
case and if the numerical model includes more than ten components, the model should be solved on the high performance parallel computing platform or supercomputer platform to guarantee convergence and stability.

\subsection{Parameters used in calculations}

The Absorptance of laser beam energy, $\eta_{1}$, is a vital parameter in direct laser deposition. The near-infrared laser energy absorptance has been estimated by Hagen-Rubens relationship [30]. Absorptance $\eta_{l}(T)$ is computed via the temperature-varying electrical resistivity of the substrate $R_{e}(T)$ as follow,

$\eta_{l}(T)=\left(8 \varepsilon_{0} \omega R_{e}(T)\right)^{1 / 2}$,

where $\omega$ is the angular frequency of the laser beam and $\varepsilon_{0}$ is the permittivity of vacuum. The resistivity $R_{e}(T)$ for liquid $38 \mathrm{MnVS}$ is [31],

$R_{e}(T)=1.125+1.438 \times 10^{-4} T$,

Due to the mixture of substrate and added powder in the melt pool, the material properties of the solutions are assumed to depend linearly on the material properties of the substrate and added powders [32],

$A_{\text {solu }}=\alpha A_{\text {sub }}+(1-\alpha) A_{\text {add }}$,

where $A_{\text {solu }}$ is the thermo-physical property of the solution, $A_{\text {sub }}$ and $A_{a d d}$ are the properties of substrate and added material, respectively. In this equation, A should be replaced by the density, thermal conductivity, specific heat and viscosity. The mixture fraction, $\alpha$, is defined the mass fraction of substrate element Fe. The material properties of the substrate and added material are present in Table 2. The data used for calculations are present in Table 3. To get the mixture-averaged diffusion coefficient $D_{i}^{m}$, the binary diffusion coefficients $D_{i k}$ should be used based on experimental results [33], which are present in Table 4.

\section{Results and discussions}

\subsection{Thermal behavior}

\subsubsection{Heat transfer and fluid flow}

Fig. 2(a)-(d) shows the computed temperature field at different times. The temperature distribution is indicated by the contour. The green arrows are the velocity vector in the melt pool. The black isotherms represent the liquidus and solidus temperature. In the initial stage of process, the temperature in the laser heated area

Table 2

Material properties of the substrate and added material.

\begin{tabular}{|c|c|c|c|}
\hline Property & $\begin{array}{l}\text { Substrate } \\
(38 \mathrm{MnVS})\end{array}$ & $\begin{array}{l}\text { Powder } \\
(\mathrm{Co}-\mathrm{Cr}-\mathrm{W})\end{array}$ & References \\
\hline Solid density $\rho_{\mathrm{s}}\left(\mathrm{kg} \mathrm{m}^{-3}\right)$ & 7400 & 8400 & {$[34]$} \\
\hline Liquid density $\rho_{l}\left(\mathrm{~kg} \mathrm{~m}^{-3}\right)$ & 6980 & 6875 & [34] \\
\hline Solidus temperature $T_{s}(\mathrm{~K})$ & 1609 & 1598 & [34] \\
\hline Liquidus temperature $T_{l}(\mathrm{~K})$ & 1768 & 1754 & [34] \\
\hline Solid specific heat $c p_{s}\left(\mathrm{~J} \mathrm{~kg}^{-1} \mathrm{~K}^{-1}\right)$ & 604 & 417 & [34] \\
\hline Liquid specific heat $c p_{l}\left(\mathrm{~J} \mathrm{~kg}^{-1} \mathrm{~K}^{-1}\right)$ & 758 & 552 & {$[34]$} \\
\hline $\begin{array}{l}\text { Solid thermal conductivity } k_{s} \\
\qquad\left(\mathrm{~W} \mathrm{~m} \mathrm{~m}^{-1} \mathrm{~K}^{-1}\right)\end{array}$ & 22 & 11 & [34] \\
\hline $\begin{array}{l}\text { Liquid thermal conductivity } k_{l} \\
\qquad\left(\mathrm{~W} \mathrm{~m} \mathrm{~m}^{-1} \mathrm{~K}^{-1}\right)\end{array}$ & 24 & 13 & [34] \\
\hline $\begin{array}{l}\text { Latent heat of fusion } L \\
\qquad\left(\mathrm{~kJ} \mathrm{~kg}^{-1} \mathrm{~K}^{-1}\right)\end{array}$ & 270 & 310 & [34] \\
\hline Dynamic viscosity $\mu$ (Pa s) & $5.5 \times 10^{-3}$ & $5.5 \times 10^{-3}$ & [12] \\
\hline $\begin{array}{l}\text { Temperature coefficient of surface } \\
\text { tension } d \sigma / d T\left(\mathrm{~N} \mathrm{~m}^{-1} \mathrm{~K}^{-1}\right)\end{array}$ & $1.0 \times 10^{-4}$ & $-4.3 \times 10^{-4}$ & [35] \\
\hline
\end{tabular}

Table 3

Data used for calculations.

\begin{tabular}{lll}
\hline Parameter & Value & References \\
\hline Laser power $Q(\mathrm{~W})$ & 700 & - \\
Beam radius $r_{b}(\mathrm{~mm})$ & 1 & - \\
Scanning speed $V_{s}(\mathrm{~mm} / \mathrm{s})$ & 10 & - \\
Mass flow rate $m_{f}(\mathrm{~g} / \mathrm{min})$ & 6.2 & - \\
Mass flow radius $r_{p}(\mathrm{~mm})$ & 2.5 & - \\
Powder catchment efficiency $\eta_{m}$ & 0.9 & - \\
Convective heat transfer coefficient $h_{c}$ & 100 & {$[12]$} \\
$\quad\left(\mathrm{W} \mathrm{m}^{-2} \mathrm{~K}^{-1}\right)$ & & \\
Emissivity $\varepsilon$ & 0.7 & {$[20]$} \\
Angular frequency of the laser $\omega\left(\mathrm{rad} \mathrm{s}^{-1}\right)$ & $1.75 \times 10^{15}$ & {$[30]$} \\
Permittivity $\varepsilon_{0}\left(\mathrm{~F} \mathrm{~m}{ }^{-1}\right)$ & $8.85 \times 10^{-12}$ & {$[30]$} \\
Ambient temperature $T_{0}(\mathrm{~K})$ & 293 & - \\
\hline
\end{tabular}

Table 4

Binary diffusion coefficients for mass transport equations [33].

\begin{tabular}{ll}
\hline Parameter & Value \\
\hline$D_{\mathrm{Fe}-\mathrm{Co}}\left(\mathrm{m}^{2} \mathrm{~s}^{-1}\right)$ & $2.1 \times 10^{-8}$ \\
$D_{\mathrm{Fe}-\mathrm{Cr}}\left(\mathrm{m}^{2} \mathrm{~s}^{-1}\right)$ & $3.1 \times 10^{-8}$ \\
$D_{\mathrm{Fe}-\mathrm{C}}\left(\mathrm{m}^{2} \mathrm{~s}^{-1}\right)$ & $5.5 \times 10^{-8}$ \\
$D_{\mathrm{Co}-\mathrm{Cr}}\left(\mathrm{m}^{2} \mathrm{~s}^{-1}\right)$ & $2.8 \times 10^{-8}$ \\
$D_{\mathrm{Co}-\mathrm{C}}\left(\mathrm{m}^{2} \mathrm{~s}^{-1}\right)$ & $2.0 \times 10^{-9}$ \\
$D_{\mathrm{Cr}-\mathrm{C}}\left(\mathrm{m}^{2} \mathrm{~s}^{-1}\right)$ & $8.0 \times 10^{-9}$ \\
\hline
\end{tabular}

increases rapidly owing to the sudden high-density laser heat flux. After the maximum temperature exceeds the solidus temperature of substrate, a liquid melt pool begins to form due to the solid-liquid phase change. Liquid metal flow in the melt pool has influence on heat transfer. The importance of convection for heat transfer can be evaluated by Peclet number,

$P e_{T}=\operatorname{Re} \times \operatorname{Pr}=\frac{\rho u L_{R}}{\mu} \times \frac{\mu}{\rho \alpha_{h}}$

where Re is Reynolds number, $P r$ is Prandtl number, $u$ is the characteristic liquid velocity in the melt pool, $L_{R}$ is the characteristic length taken as the melt pool radius, $\alpha_{h}$ is the material thermal diffusivity. Computed velocity fields of melt pool at different times are shown in the Fig. 3(a)-(d). The velocity magnitude is indicated by the contour. In the initial period of process as shown in Fig. 3(a), the velocity magnitude of liquid metal is smaller (maximum $0.17 \mathrm{~m} / \mathrm{s}$ ), so the $P e_{T}$ is smaller than 5 in this condition. Conduct plays an important role in heat transfer, resulting in an approximate hemispherical melt pool boundary. With the convection gets stronger, the maximum velocity in the melt pool exceeds $0.5 \mathrm{~m} / \mathrm{s}$ when the melt pool is almost fully developed as shown in Fig. 3(d). At this condition, the $P e_{T}$ in the melt pool is calculated to be 100 , thus the heat transfer is dominated by thermal convection. Since the temperature coefficient of surface tension is negative, the liquid metal moves from the center of the laser beam toward the periphery of the melt pool, enhancing heat transport in the melt pool. As a result, the temperature gradients in the melt pool are much lower than the case without considering the fluid flow. Owing to the strong outward flow, the boundary of melt pool becomes wide but shallow.

\subsubsection{Solidification characteristics}

Temperature field significantly impacts the solidification behavior of deposited track. Two key characteristics affect the solidified microstructure, namely temperature gradient $(G)$ and solidification growth rate $(R)$. The effects of the $G$ and $R$ on the morphology and scale of the solidified microstructure have been studied as shown in Fig. 4. The cooling rate $(G \times R)$ influence the scale of the solidification microstructure. Higher cooling rate provides finer size of dendrites. On the other hand, as the $G / R$ decreases, 

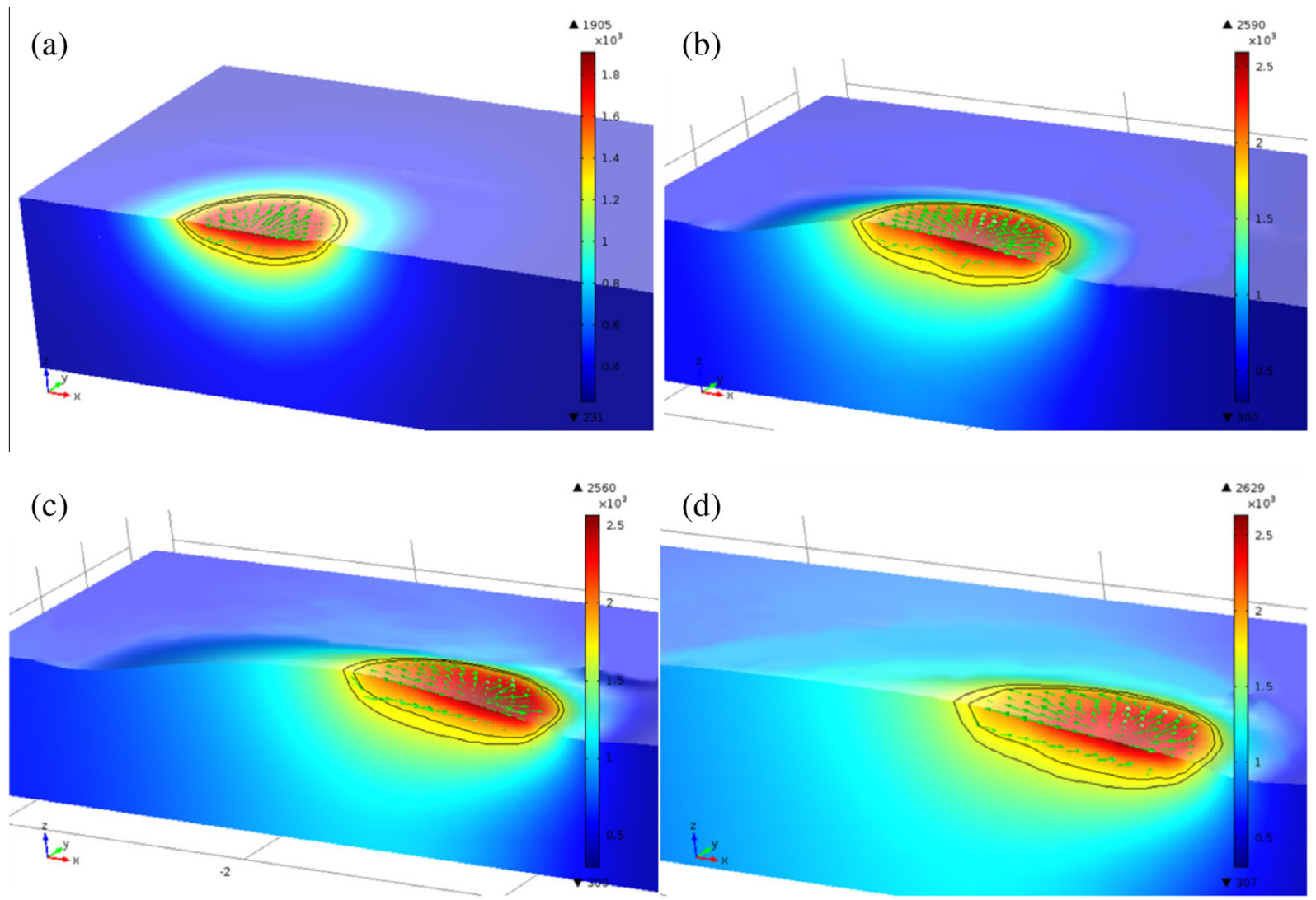

Fig. 2. Computed temperature distribution at different times: (a) $10 \mathrm{~ms}$, (b) $300 \mathrm{~ms}$, (c) $500 \mathrm{~ms}$, and (d) $700 \mathrm{~ms}$.
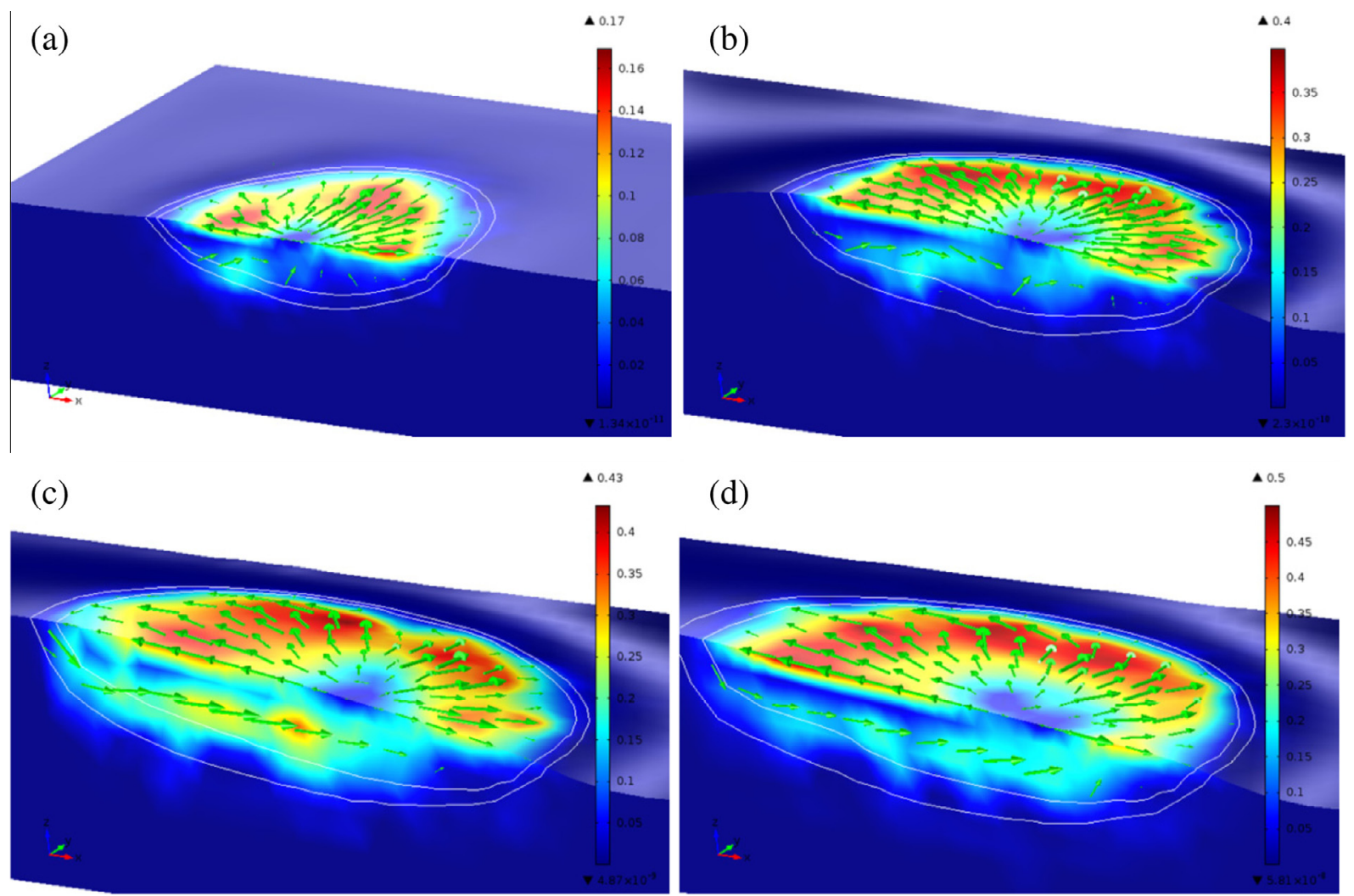

Fig. 3. Computed velocity magnitude at different times: (a) $10 \mathrm{~ms}$, (b) $300 \mathrm{~ms}$, (c) $500 \mathrm{~ms}$, and (d) $700 \mathrm{~ms}$. 


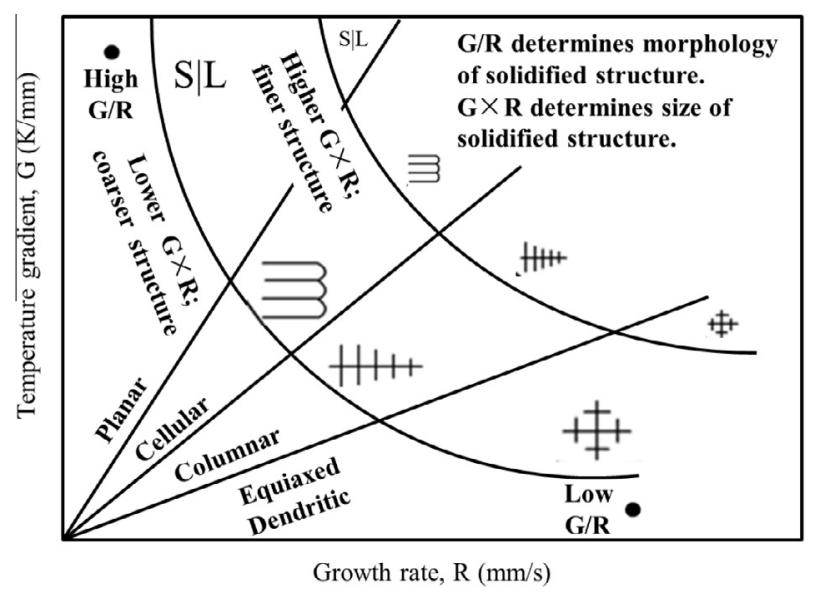

Fig. 4. The effects of the $G$ and $R$ on the morphology and scale of the solidified microstructure [36].

the morphology of the microstructure varies from planar front to cellular dendrites to columnar dendrites to equiaxed dendrites.

It is important to note that $G$ is the temperature gradient normal to the solidification front and $\mathrm{R}$ is the velocity of the solidification front, which can be expressed below,

$$
G=\nabla T \cdot \hat{\boldsymbol{n}}
$$

$R=V s \cdot \boldsymbol{i} \cdot \hat{\boldsymbol{n}}$

where $\hat{\boldsymbol{n}}$ is the unit normal vector of the liquidus front, $\boldsymbol{i}$ is unit vector of scanning direction.

According to the computed transient temperature field, both the cooling rate $(G \times R)$ and $G / R$ can be calculated to predict the morphology and scale of the solidification microstructure. These parameters are calculated for every position along the solidification front, which is a 3D surface. To gain insight into the microstructure of the solidified deposited track, the track is cross-sectioned at the plane of deposition width. After obtaining the normal vector of the liquidus front of the melt pool and computing $G$ and $R$ on the liquidus front, values of $G$ and $R$ are projected to the cross-section of deposition track to compute the solidification characteristics $G \times R$ and $G / R$. Fig. 5(a)-(d) shows the contours of $G, R, G / R$ and $G \times R$ on the cross-section, respectively. Due to the strong outward Marangoni flow as shown in Fig. 3, the melt pool is shallow but wide and the solidification front is mostly flat. $G$ increases twofold from $1352 \mathrm{~K} / \mathrm{mm}$ along the periphery to $650 \mathrm{~K} /$ $\mathrm{mm}$ in the center of the cross-section and $R$ changes fiftyfold from $0.2 \mathrm{~mm} / \mathrm{s}$ at the bottom to $9.8 \mathrm{~mm} / \mathrm{s}$ at the surface of deposited track. So the solidification characteristic is basically affected by the larger variation of $R$. Fig. 5(c) and (d) shows the contour of $G /$ $R$ and $G \times R$ over the cross-section of deposited track, respectively. The results give an idea of the morphology and scale of the microstructure expected in the solidified track. Higher $G / R$ and lower $G \times R$ are observed at the bottom of the deposited track, on the contrary, lower $G / R$ and higher $G \times R$ are noticed at the top of the deposited track. It is illustrated that the morphology of the microstructure is prone to planar front and the scale of microstructure is coarser at the bottom of the deposited track. Whereas the morphology of the microstructure is prone to equiaxed dendrites and the scale of microstructure is finer at the top of the deposited track. For validating the numerical predictions, Fig. 6 presents the experimental determined cross-section of deposited track and the microstructure in the point of A, B and C, which locate the bottom, the center and the top of cross-section, respectively. The calculated $G / R$ and $G \times R$ are also marked in the figure. At the bottom of deposited track, the planar front can be notice. At the central zone, the columnar and coarser dendrites are observed. At the top of cross-section of deposited track, the equiaxed and finer dendrites are obtained. The experimental result agrees excellently with the simulation tendency.

\subsection{Multicomponent mass transfer}

\subsubsection{Multicomponent concentration fields}

Besides the solidified microstructure, the composition distribution also distinguished affects the properties of cladding layer, so the mass transfer and composition profile should be fully understood. During direct laser deposition process, powders addition lead to the redistribution of solute in the melt pool. The mixture and transport of various alloy components in the melt pool plays a vital role for the final composition profile. Fig. 7(a)-(d) shows the calculated mass transport of Co in direct laser deposition at various times. The concentration of element $\mathrm{Co}$ is indicated by weight fraction. The black isotherms represent the liquidus and solidus temperature.

During direct laser deposition process, mass transfer in the melt pool is based on convection and diffusion. The dimensionless number $P e_{m}$ describes the relative importance of these two mechanisms [20],

$P e_{m}=\frac{u L_{R}}{D}$

which is on the order of $10^{4}$, so convection is the main mass transfer mechanism in the melt pool. Thus, it is essential to take into account the convection mass transport in the model. It can be seen from Fig. 7(a) that at the time of $10 \mathrm{~ms}$, the element Co begins to mix with the substrate. Due to the outward Marangoni flow (see Fig. 3), the element Co tends to accumulate on the periphery of the melt pool and the concentration at the bottom of melt pool is almost zero at this moment. At the time of $300 \mathrm{~ms}$ as shown in Fig. 7(b), the concentration of Co increases rapidly. The distribution of $\mathrm{Co}$ is non-uniform in the melt pool. The concentration on the trailing edge and periphery of melt pool is higher than other parts. At the time of $500 \mathrm{~ms}$ as shown in Fig. 7(c), with the movement of laser beam, the maximum weight fraction of Co is $20 \mathrm{wt} \%$. Owing to the strong Marangoni convection, which is a surface tension driven flow, the distribution of Co is almost uniform at the top surface of melt pool. However, an unmixed zone is observed at the bottom of melt pool. The distribution of element is fairly non-uniform in this region. The unmixed zone is near the bottom fusion boundary where the convection is frictionally dissipated due to the presence of solidified dendrites. The insufficient mixture leads to the nonuniform distribution of element in the unmixed zone. At $700 \mathrm{~ms}$ as shown in Fig. 7(d), the concentration of Co is uniform and is about $32 \mathrm{wt} \%$ except in the unmixed zone.

Fig. 8 shows the multicomponent composition profile in the longitudinal of deposited track. Fig. 8(a) and (b) presents the composition profile of substrate material (i.e. Fe and C). Fig. 8(c) and (d) shows the added material (i.e. Co and $\mathrm{Cr}$ ). It can be seen that in the initial stage of direct laser deposition process, the distribution of elements in the melt pool is un-uniform, due to insufficient time for mixing and lower convection. Then the composition distributions are gradually uniformity. The unmixed zone is also observed at the bottom of deposited track. Fig. 9 shows variation of composition profile of $\mathrm{Fe}, \mathrm{Co}$, and $\mathrm{Cr}$ along a scanning track (set in Fig. 8 (d)) for two cases: one with diffusion, and the other without diffusion. The experimental composition distributions by EDS are also marked in Fig. 9. As seen in Fig. 9, in the initial stage, due to the mass addition and high concentration gradient in the melt pool, the rapidly transport and mixture of substrate material $(\mathrm{Fe}, \mathrm{C}$ ) and added material $(\mathrm{Co}, \mathrm{Cr})$ take place in the melt pool. Due to 


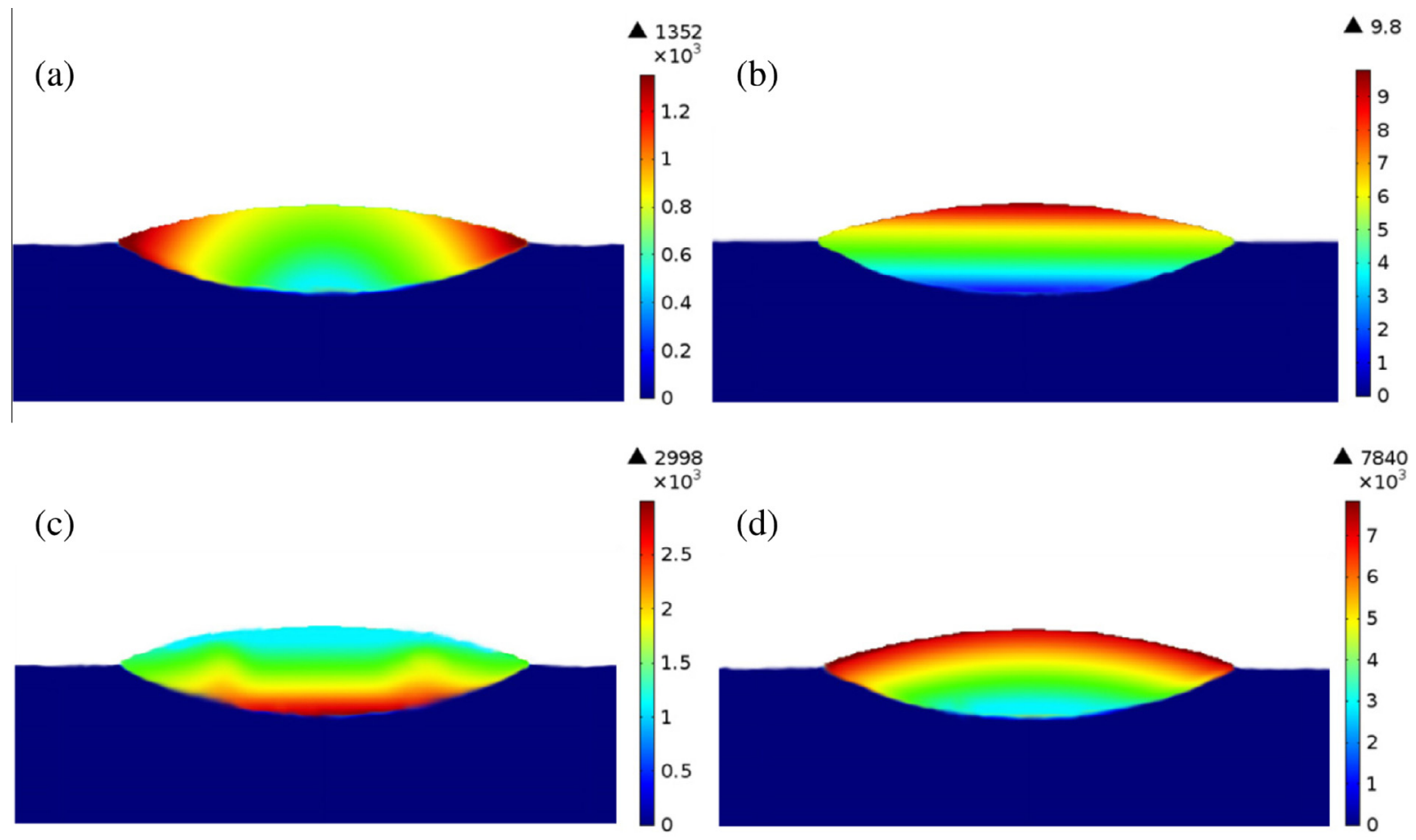

Fig. 5. Computed contours of solidification characteristics: (a) temperature gradient $G$, (b) solidification growth rate $R$, (c) $G / R$, and (d) cooling rate $G \times R$.
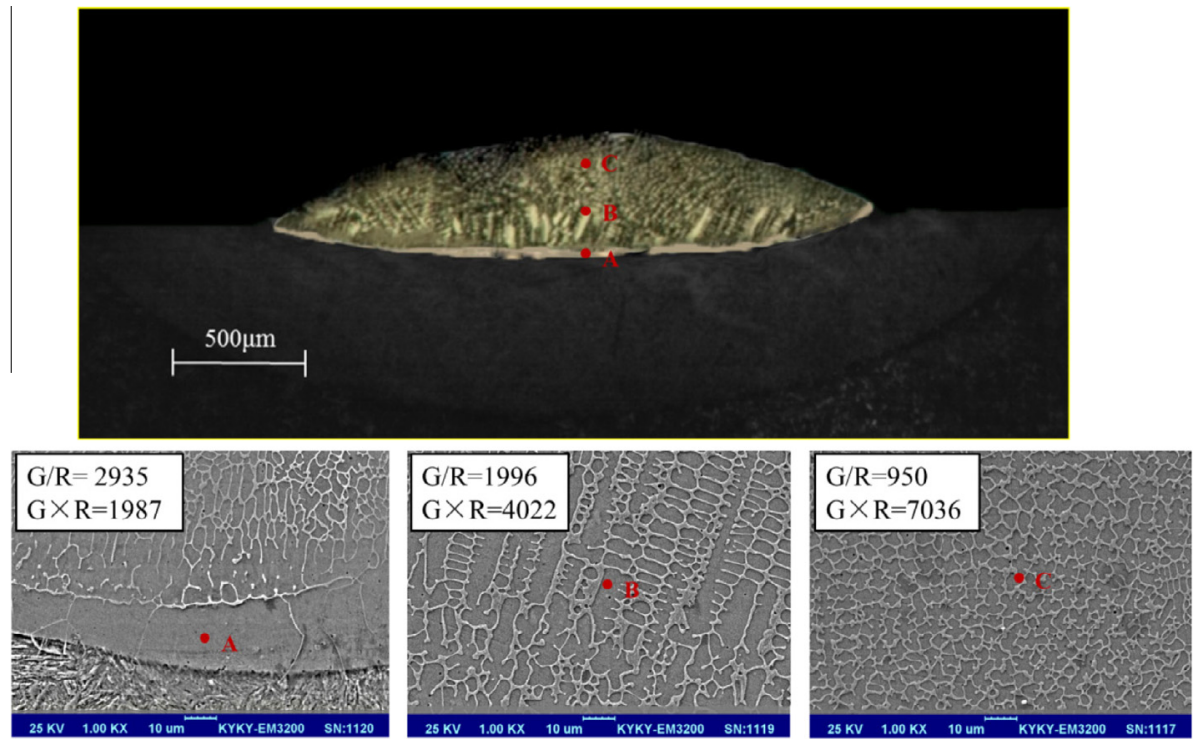

Fig. 6. Experimental cross-section of deposited track and the microstructure in the points of A, B and C.

the difference of concentration and molar mass, the mass transfer rate for various elements is different. The mass transport rate of Fe is highest. With the development of melt pool, the mass transfer rate rapidly decreases and the concentration of Fe gradually increases while the concentration of $\mathrm{Co}$ and $\mathrm{Cr}$ gradually decreases. It is mainly resulted from the melt pool widen and deepen during the direct laser deposition as shown in Fig. 10. More bulk of substrate material is melted into the melt pool, resulting in the increase of substrate elements and decrease of powder elements.

It is worth to note from the Fig. 9, in the initial period of melt pool formation, due to the low velocity in the melt pool, the effect of diffusion on mass transfer cannot be neglected for multicomponent alloys system. The calculation with diffusion agrees better with the experimental result. As the development of melt pool, due to the strong Marangoni flow, the convection is the main mass transfer mechanism in the melt pool.

\subsubsection{Experimental composition profile}

In order to validate the numerical model, firstly, geometrical validation for the model should be done and then more detailed comparisons, such as composition profile, can be made. The experimental cross-section of deposited track is compared with the calculated geometry in Fig. 11. A little deviation between computed dimensions of melt pool and the experimental cross-section of deposited track can be seen in Fig. 11. During the laser cladding process, many factors will affect dimensions of melt pool, such as 

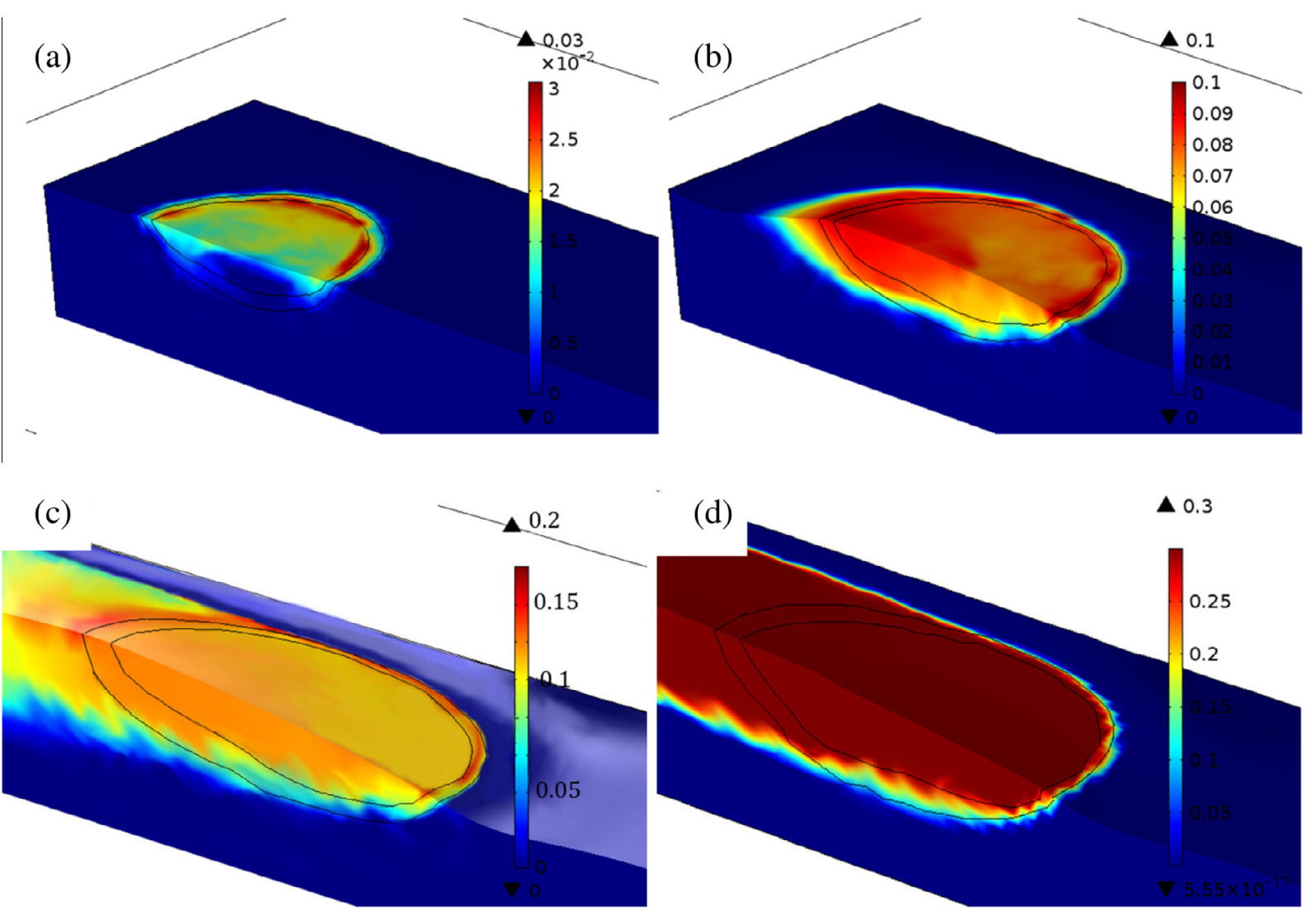

Fig. 7. Computed concentration profile of Co at different times: (a) $10 \mathrm{~ms}$, (b) $300 \mathrm{~ms}$, (c) $500 \mathrm{~ms}$, and (d) $700 \mathrm{~ms}$.
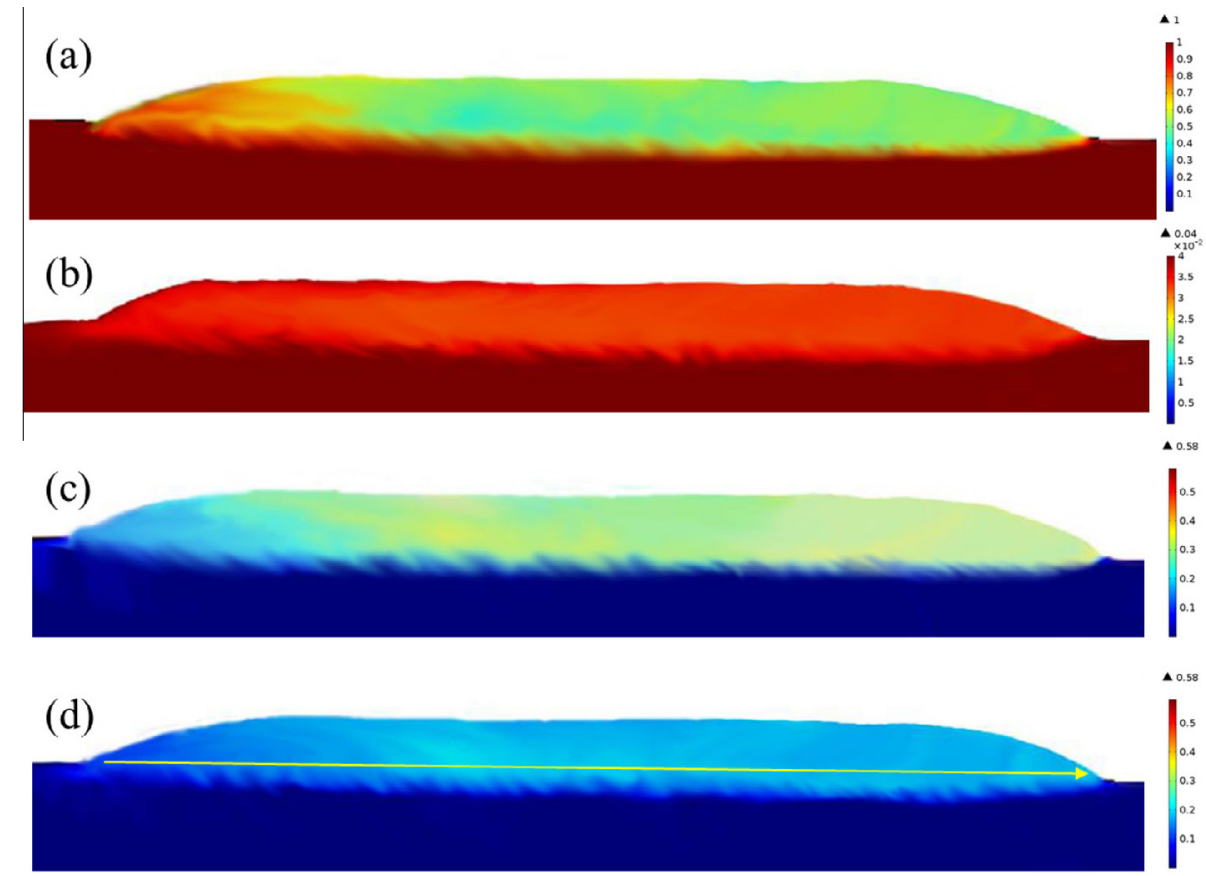

Fig. 8. Multicomponent composition profile in the longitudinal of cladding bead (a) element Fe, (b) element C, (c) element Co, (d) element Cr.

absorptivity, effective powder flow rate, material properties (temperature-independent in this study), overestimated driving force of fluid flow.
Fig. 12 shows the computed and experimental composition distributions. The scanning track of EDS is present in Fig. 11(b). The weight fractions of alloy elements for points A, B and C are shown 


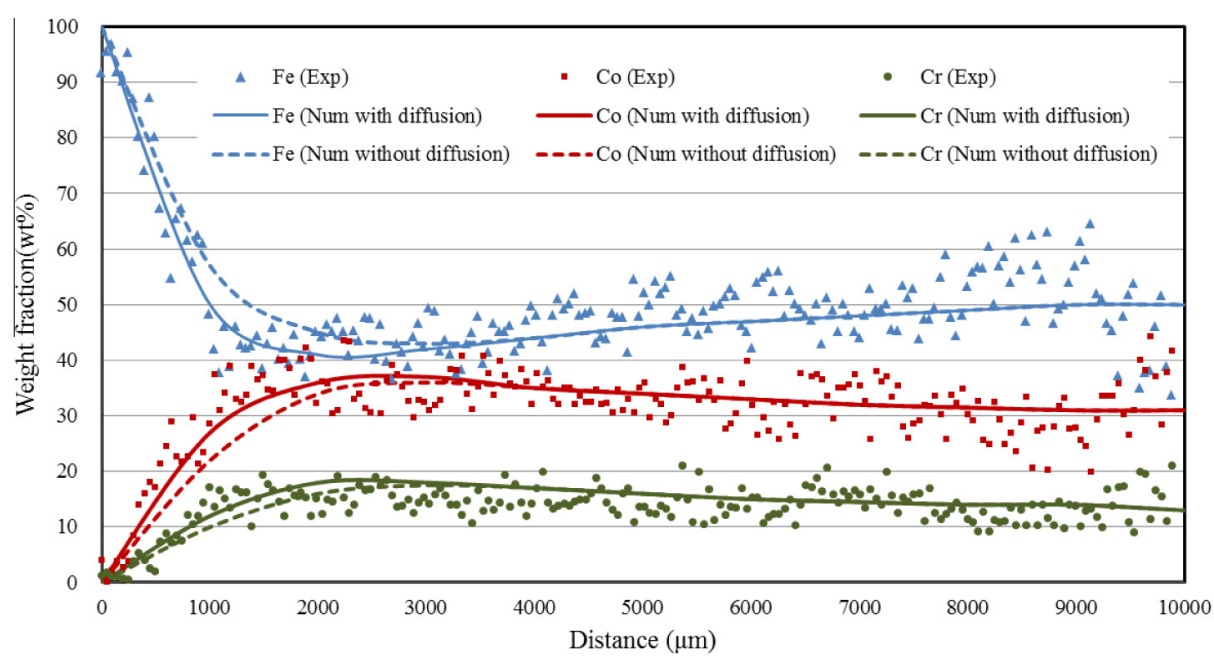

Fig. 9. Weight fraction of $\mathrm{Fe}, \mathrm{Co}$, and $\mathrm{Cr}$ along the scanning track.

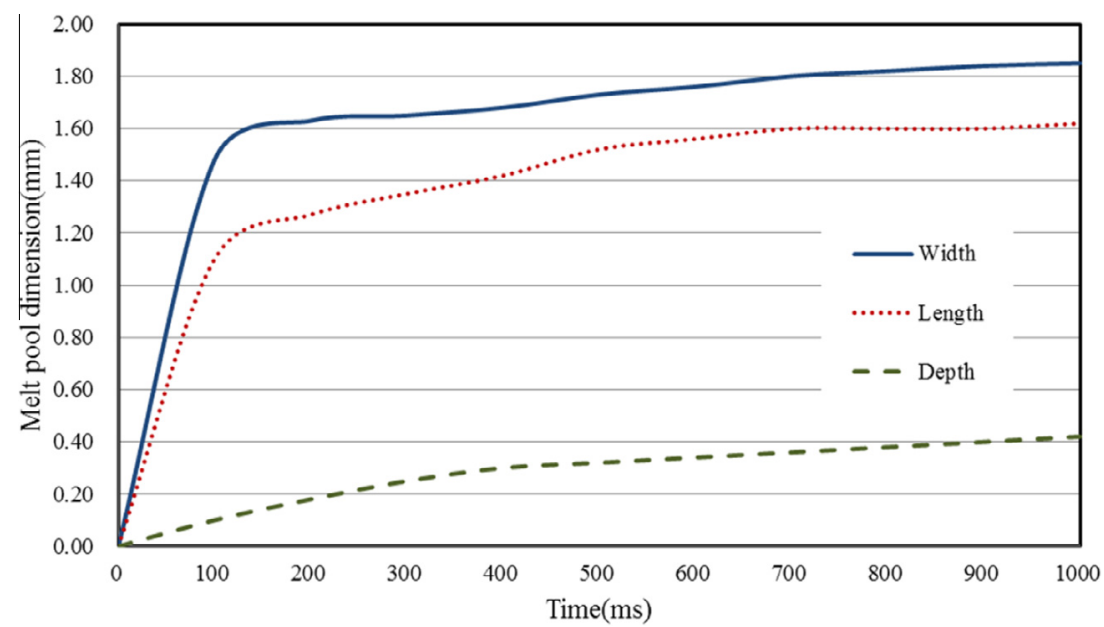

Fig. 10. Computed melt pool dimension at different times.

(a)
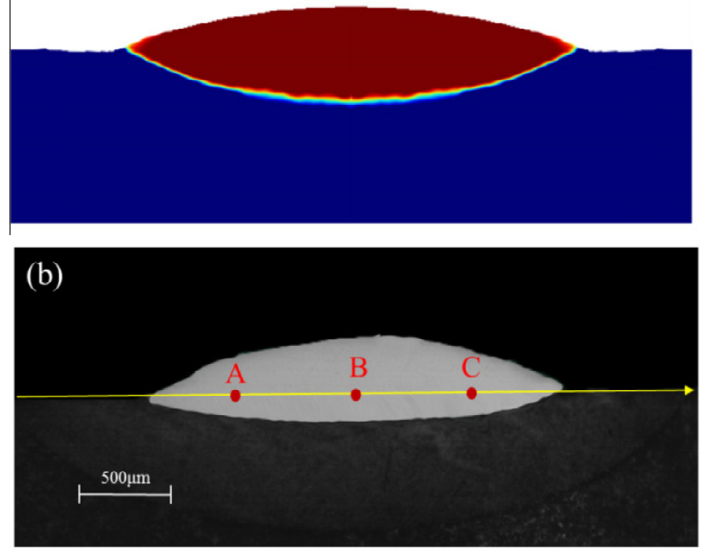

Fig. 11. Computed and experimental cross-sections of melt pool (a) from numerical simulation, (b) from experiment.

in Table 5. The computed results agree well with the experimental results. Litter deviations between computed concentrations and experimental results are found. It is mainly resulted from the sim- plicity of the numerical model. The effect of temperature on the thermo-physics properties is ignored. The laser beam energy and powder flow are considered to be Gaussian distribution. As seen in Fig. 12, the experimental compositions distribution in the cross-section are asymmetry. The asymmetry of the real powder flow, vibration during experimental process, and compositional heterogeneity of substrate and powder may lead to the asymmetry. Even so, the relative errors for three points are less than $17 \%$, verifying the numerical model proposed in this study. As seen in Fig. 11, the dimension of the melt pool $(1.8 \mathrm{~mm})$ is smaller than the diameter of laser spot $(2 \mathrm{~mm})$, owing to the higher thermal conductivity of solid substrate.

In the numerical results, the concentration distribution is almost uniform in the most regions of cross-section. However, based on the experimental measurement, the concentration distribution is fluctuant from one point to the other as shown in Fig. 12 and Table 5. In fact, in real solidification process of multicomponent alloys system, microsegregation toward the cell boundaries will occur. Due to the high cooling rates, the elementals are incomplete solute diffusion in the solid phase. This microsegregation phenomenon didn't consider in this study. Thus, the present model only can obtain the macroscopic composition profile. The microscopic composition profile should be obtained by considering the microsegregation phenomenon in future study. 


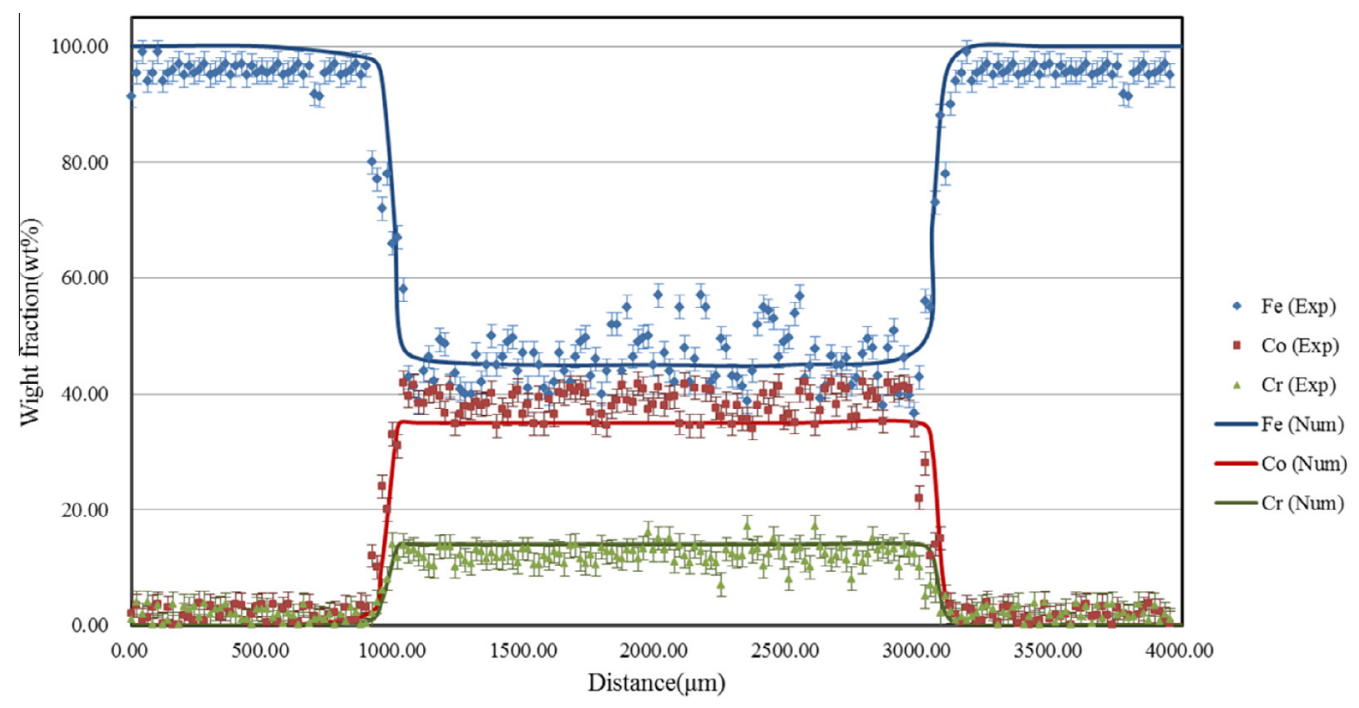

Fig. 12. Computed and experimental weight fraction of $\mathrm{Fe}, \mathrm{Co}$, and $\mathrm{Cr}$ in the cross-section.

Table 5

Computed and experimental weight fraction of $\mathrm{Fe}, \mathrm{Co}$, and $\mathrm{Cr}$ for different points of cross-section (wt\%).

\begin{tabular}{llll}
\hline Element Fe & A & B & C \\
\hline Experimental & 41 & 48 & 43 \\
Calculated & 45 & 46 & 45 \\
Relative error & $10 \%$ & $4 \%$ & $5 \%$ \\
Element Co & $\mathrm{A}$ & $\mathrm{B}$ & $\mathrm{C}$ \\
\hline Experimental & 36 & 39 & 40 \\
Calculated & 35 & 36 & 35 \\
Relative error & $3 \%$ & $8 \%$ & $13 \%$ \\
Element Cr & $\mathrm{A}$ & $\mathrm{B}$ & $\mathrm{C}$ \\
\hline Experimental & 13 & 16 & 12 \\
Calculated & 14 & 15 & 14 \\
Relative error & $8 \%$ & $6 \%$ & $17 \%$ \\
\hline
\end{tabular}

\section{Conclusions}

The thermal behavior, fluid flow, melting-solidification and multicomponent mass transfer are investigated utilizing a proposed 3D heat and mass transfer numerical model. The solidified microstructure of the deposited track are predicted and explained by the transient temperature distribution. The multicomponent mass transfer is considered into the model. The computed melt pool geometry and macroscopic composition distributions are in good agreement with the experimental results. Some valuable conclusions are as follows:

(1) In the initial stage of direct laser deposition, the Peclet number for heat transfer is smaller than 5 , so conduct plays an important role in heat transfer, resulting in an approximate hemispherical melt pool boundary. When the convection in the melt pool is fully developed, the Peclet number for heat transfer is greater than 100 . The heat transfer in the melt pool is dominated by convection.

(2) $\mathrm{G}$ increases twofold from $1352 \mathrm{~K} / \mathrm{mm}$ along the periphery to $650 \mathrm{~K} / \mathrm{mm}$ in the center of the solidified track and R changes fiftyfold from $0.2 \mathrm{~mm} / \mathrm{s}$ at the bottom to $9.8 \mathrm{~mm} / \mathrm{s}$ at the surface of the solidified track. Since the $G / R$ decreases and $G \times R$ increases from the bottom to the top of the solidified track, the morphology of the microstructure changes from planar front to columnar dendrites to equiaxed dendrites and the grain size decreases.
(3) In the initial stage of direct laser deposition, the rapidly transport and mixture of substrate material and added material occur in the melt pool. As the melt pool is developed, the mass transfer rate rapidly decreases. The Peclet number for mass transfer is on the order of $10^{4}$, so convection is the main mechanism for mass transport of alloy elements in the melt pool. An unmixed zone is observed near the bottom of melt pool where the convection is frictionally dissipated due to the presence of solidified dendrites. The insufficient mixture leads to the non-uniform distribution of element in the unmixed zone.

(4) The discrepancy of calculated and experimental element concentration is less than $17 \%$. The proposed model is beneficial in the understanding of the heat and mass transport phenomena and predicting the optimized powder system and process parameters in direct laser deposition. It is reasonable to expect that this model will be conveniently developed to simulate the multi-pass and multi-layer direct laser deposition and take into account more components in the future.

\section{Acknowledgment}

This work was supported by the National Natural Science Foundation of China under grant Nos. 11272316, 11272317 and 11502269.

\section{References}

[1] S.A. David, T. DebRoy, Current issues and problems in welding science, Science 257 (1992) 497-502.

[2] E. Toyserkani, S. Corbin, A. Khajepour, Laser Cladding, CRC, Canada, 2005.

[3] S. Wen, Y.C. Shin, Modeling of transport phenomena during the coaxial laser direct deposition process, J. Appl. Phys. 108 (2010) 044908.

[4] Y. Huang, X. Zeng, Investigation on cracking behavior of Ni-based coating by laser-induction hybrid cladding, Appl. Surf. Sci. 256 (2010) 5985-5992.

[5] V. Ocelík, U. Oliveira, M. Boer, et al., Thick Co-based coating on cast iron by side laser cladding: analysis of processing conditions and coating properties, Surf. Coat. Technol. 201 (2007) 5875-5883.

[6] S. Zhou, X. Dai, X. Zeng, Effects of processing parameters on structure of Nibased WC composite coatings during laser induction hybrid rapid cladding, Appl. Surf. Sci. 255 (2009) 8494-8500.

[7] X. Wu, Y. Hong, Fe-based thick amorphous-alloy coating by laser cladding, Surf. Coat. Technol. 141 (2001) 141-144.

[8] C. Huang, Y. Zhang, J. Shen, et al., Thermal stability and oxidation resistance of laser clad TiVCrAlSi high entropy alloy coatings on Ti-6Al-4V alloy, Surf. Coat. Technol. 206 (2011) 1389-1395. 
[9] S. Li, Q.W. Hu, X.Y. Zeng, S.Q. Ji, Effect of carbon content on the microstructure and the cracking susceptibility of Fe-based laser-clad layer, Appl. Surf. Sci. 240 (2005) 63-70.

[10] Y. Hu, X. He, G. Yu, Z. Ge, C. Zheng, W. Ning, Heat and mass transfer in laser dissimilar welding of stainless steel and nickel, Appl. Surf. Sci. 258 (2012) 5914-5922.

[11] H. Qi, J. Mazumder, H. Ki, Numerical simulation of heat transfer and fluid flow in coaxial laser cladding process for direct metal deposition, J. Appl. Phys. 100 (2006) 024903.

[12] X. He, J. Mazumder, Transport phenomena during direct metal deposition, J. Appl. Phys. 101 (2007) 053-113.

[13] A. Kumar, S. Roy, Effect of three-dimensional melt pool convection on process characteristics during laser cladding, Comp. Mater. Sci. 46 (2009) 495-506.

[14] Y.S. Lee, M. Nordin, S.S. Babu, et al., Influence of fluid convection on weld pool formation in laser cladding, Weld. J. 93 (2014) 292S-300S.

[15] W. Gao, S. Zhao, Y. Wang, et al., Numerical simulation of thermal field and Febased coating doped Ti, Int. J. Heat Mass Transfer 92 (2016) 83-90.

[16] A. Emamian, M. Alimardani, A. Khajepour, Correlation between temperature distribution and in situ formed microstructure of Fe-TiC deposited on carbon steel using laser cladding, Appl. Surf. Sci. 258 (2012) 9025-9031.

[17] D.V. Bedenko, O.B. Kovalev, I. Smurov, et al., Numerical simulation of transport phenomena, formation the bead and thermal behavior in application to industrial DMD technology, Int. J. Heat Mass Transfer 95 (2016) 902-912.

[18] S. Morville, M. Carin, P. Peyre, et al., 2D longitudinal modeling of heat transfer and fluid flow during multilayered direct laser metal deposition process, J. Laser Appl. 24 (2012) 032008.

[19] Y. Huang, Y. Yang, G. Wei, et al., Boundary coupled dual-equation numerical simulation on mass transfer in the process of laser cladding, Chin. Opt. Lett. 6 (2008) 356-360

[20] X. He, L. Song, G. Yu, Solute transport and composition profile during direct metal deposition with coaxial powder injection, Appl. Surf. Sci. 258 (2011) $898-907$.

[21] X. He, G. Yu, J. Mazumder, Temperature and composition profile during double-track laser cladding of H13 tool steel, J. Phys. D Appl. Phys. 43 (2009) 015502.

[22] S.D. Felicelli, D.R. Poirier, P.K. Sung, A model for prediction of pressure and redistribution of gas-forming elements in multicomponent casting alloys, Metall. Mater. Trans. B-Proc. Metall. Mater. Proc. Sci. 31 (2000) 1283-1292.
23] S. Postel, S. Wessel, T. Keil, et al., Multicomponent mass transport in organic solvent nanofiltration with solvent mixtures, J. Membr. Sci. 466 (2014) $361-$ 369.

[24] S. Asai, I. Muchi, Theoretical analysis and model experiments on the formation mechanism of channel-type segregation, Trans. Iron Steel Inst. Jpn. 18 (1978) 90-98.

[25] W.D. Bennon, F.P. Incropera, A continuum model for momentum, heat and species transport in binary solid-liquid phase change systems-I. Model formulation, Int. J. Heat Mass Transfer 30 (1987) 2161-2170.

[26] W.D. Bennon, F.P. Incropera, A continuum model for momentum, heat and species transport in binary solid-liquid phase change systems-I. Model formulation, Int. J. Heat Mass Transfer 30 (1987) 2171-2187.

[27] A. Kar, J. Mazumder, Model for nonequilibrium partitioning during rapid solidification of binary concentrated solutions, Acta Metall. Mater. 40 (1992) 1873-1881.

[28] C.F. Curtiss, R.B. Bird, Multicomponent diffusion, Ind. Eng. Chem. Res. 38 (1999) 2515-2522.

[29] R.K.C. Chan, A generalized arbitrary Lagrangian-Eulerian method for incompressible flows with sharp interfaces, J. Comput. Phys. 17 (1975) 311 331.

[30] J. Xie, A. Kar, J.A. Rothenflue, et al., Temperature-dependent absorptivity and cutting capability of $\mathrm{CO}_{2}$, Nd: YAG and chemical oxygen-iodine lasers, J. Laser Appl. 9 (1997) 77-85.

[31] R.W. Cohen, B. Abeles, Efficiency calculations of thermoelectric generators with temperature varying parameters, J. Appl. Phys. 34 (1963) 1687-1688.

[32] A. Bahrami, B.T. Helenbrook, D.T. Valentine, et al., Fluid flow and mixing in linear GTA welding of dissimilar ferrous alloys, Int. J. Heat Mass Transfer 93 (2016) 729-741.

[33] C. Guminski, Diffusion Coefficients in Liquid Metals at High Dilution, Springer United States, 1995.

[34] K.C. Mills, Recommended Values of Thermophysical Properties for Selected Commercial Alloys, Woodhead Publishing, 2002.

[35] P. Sahoo, T. DebRoy, M.J. McNallan, Surface tension of binary metal-surface active solute systems under conditions relevant to welding metallurgy, Metall. Trans. B 19 (1988) 483-491.

[36] J.C. Lippold, Welding Metallurgy and Weldability, John Wiley \& Sons, 2014 